\title{
Structural stability studies of graphene in sintered ceramic nanocomposites
}

\author{
Fawad Inam, ${ }^{\mathrm{a}, *}$, Thuc Vo ${ }^{\mathrm{a}}$, Badekai R. Bhat ${ }^{\mathrm{b}}$ \\ ${ }^{\mathrm{a}}$ Northumbria University, Faculty of Engineering and Environment, Department of Mechanical and Construction Engineering, \\ Newcastle upon Tyne NE1 8ST, United Kingdom \\ ${ }^{\mathrm{b}}$ National Institute of Technology Karnataka, Department of Chemistry, Catalysis and Materials Laboratory, Surathkal, Srinivasanagar 575025, India
}

\section{Abstract}

The post-sintering structural stability of graphene in alumina nanocomposites synthesised by Spark Plasma Sintering (SPS) and Hot Pressing (HP) was compared. Raman spectroscopy, thermogravimetric analyses and electrical conductivity analyses were conducted to characterise degradation of graphene due to the utilisation of different sintering techniques and conditions. Scanning Electron Microscopy confirmed good dispersion of graphene in SPSed and HPed sample. Graphene in SPSed and HPed nanocomposite samples sintered using longer durations (60 $\mathrm{min})$ were found to possess higher crystallinity, thermal stability and electrical conductivity as compared to SPSed samples sintered using shorter sintering durations (10-20 min). This was attributed to the thermally induced graphitisation caused by longer sintering durations, which was lacking in SPSed samples processed using shorter sintering durations and lower temperature. No additional effect of DC pulsed current on the structural stability of graphene for nanocomposites were observed for samples prepared by SPS.

Keywords: A. Hot pressing; Graphene; Alumina; Structural stability; SPS

\section{Introduction}

The addition of graphene in ceramics is becoming a widely researched area because of its superlative nature and significant positive contribution to ceramics' performance. Over the past few years, graphene has attracted enormous research attention for its very mechanical and thermal properties and exceptionally high electron mobility [1]. Significant improvements in the mechanical, thermal and electrical properties of ceramics nanocomposites filled with graphene. Graphene has been added in ceramics likes cordierite [2], silicon carbide [3], silicon nitride [4], tantalum carbide [5], alumina [6], zirconium diboride [7], zirconia [8], boron nitride [9] to enhance not only electrical properties but also thermal conductivity, refractory, mechanical, antifriction, anticorrosive and biocompatibility properties for diverse applications [10]. For example, a remarkable $235 \%$ improvement in fracture toughness was reported for by the addition of only $1.5 \mathrm{vol} \%$ of graphene in silicon nitride [4]. Zhou et al. [2]

\footnotetext{
*Corresponding author. Tel.: +44 1912273741.
}

reported an increase of 8 orders of magnitude and 3.7 times in the electrical and thermal conductivity of cordierite ceramic respectively. Similarly, zirconium diboride filled with graphene, sintered at $1900{ }^{\circ} \mathrm{C}$, was studied by Yadhukulakrishnan et al. [7] for possible high temperature barrier applications for space vehicles during the re-entry event.

Whilst much of the emphasis is on the improvement of thermal, electrical and mechanical properties, there is no research about the graphene's structural health after sintering. For carbon nanotubes, structural and chemical degradation of carbon nanotubes during non-SPS techniques has been widely reported in the literature due to the relatively long sintering time (3-10 h) and high temperatures involved $\left(>850{ }^{\circ} \mathrm{C}\right)$ in the sintering process [11-18]. Therefore, it is widely perceived in the ceramic community, that graphene would be degraded if non-SPS techniques are used for processing ceramic-graphene nanocomposites.

There are very few research papers reporting the use of non-SPS techniques for processing ceramic-graphene or ceramic-graphene oxide nanocomposites with improved characteristics [19-23]. For example, Rutkowski et al. [19] used conventional hot-pressing for 
processing silicon nitride-graphene nanocomposite and reported improvement in thermal properties [19]. Recently, Mehrali et al. [21] produced calcium silicate-reduced graphene oxide by Hot Isostatic Pressing (HIP). Adding reduced graphene oxide to pure calcium silicate increased the hardness of the material by similar to $40 \%$, the elastic modulus by similar to $52 \%$, and the fracture toughness by similar to $123 \%$ [21]. Kvetková et al. [22] compared gas pressure sintering and HIP for processing silicon nitridegraphene nanocomposites and reported mechanical properties of the sintered nanocomposites. Similarly, Tapaszto et al., prepared silicon nitride-graphene nanocomposites by SPS and HIP techniques [23]. In comparison to SPSed nanocomposites, lower elastic modulus, fracture toughness and Vickers hardness was observed for silicon nitride-graphene nanocomposites due to the presence of a weaker beta phase in HIPed sample [23]. However, in all these research papers [19-23], no comments were made on the structural and chemical stability of graphene in any of these reports.

In this study, Raman spectroscopy, Thermogravimetric analyses and electrical conductivity analyses were conducted to characterise degradation of graphene due to the utilisation of different sintering techniques and conditions. Particularly, Raman spectroscopy has been used previously by Centeno et al. [24] to study in detail the orientation of graphene in the graphene/alumina composites and to evaluate and optimise the in situ graphene thermal reduction process in the SPS. Similarly, Badaran et al. [20] characterised reduction of graphene oxide using Raman spectroscopy and Fourier transform infrared spectroscopy (FTIR) for processing hydroxyapatite-graphene nanocomposite. However, no comments were made on the structural quality and crystallinity of graphene in these reports and no comparisons were made with other sintering techniques. To date, there is no report comparing the effect of sintering process on the structural and chemical stability of graphene after processing of ceramic-graphene nanocomposites. Therefore, in this study, we systematically compared the effect of processing techniques (i.e. SPS and HP) on the structural and chemical stability of alumina-graphene nanocomposites.

\section{Experimental details}

Alumina and alumina-3 vol\% graphene nanocomposites were sintered. Graphene nanopowder (chopped nanoribbons flakes produced by the CVD pyrolysis of a solution containing ethanol, ferrocene and thiopene as reported in [25]) were dispersed in dimethylformadie, DMF [26] using high power tip ultrasonication for 45 minutes and then hand-mixed with alumina nanopowder (Sigma-Aldrich, UK: gamma phase; particle size $<50 \mathrm{~nm}$; surface area $35-43 \mathrm{~m}^{2} \mathrm{~g}^{-1}$; melting point $2040{ }^{\circ} \mathrm{C}$; and density $3.97 \mathrm{~g} \mathrm{~cm}^{-3}$ ) for $10 \mathrm{~min}$. The liquid mixture was rotation ball milled for $8 \mathrm{~h}$. It was then dried at $65{ }^{\circ} \mathrm{C}$ for $12 \mathrm{~h}$ using a rotary drier containing milling media ( $4 \mathrm{~mm}$ alumina balls), followed by vacuum oven drying at $100{ }^{\circ} \mathrm{C}$ for $60 \mathrm{~h}$. To avoid re-agglomeration of graphene during lengthy drying, the alumina balls (milling media) was added during rotary drying. The dried nanocomposite powder was ground and sieved at 150 mesh and then placed again in the vacuum oven at $100{ }^{\circ} \mathrm{C}$ for another $60 \mathrm{~h}$ to thoroughly extract the solvent. Nanocomposite pellets (diameter $20 \mathrm{~mm}$ and thickness $4 \mathrm{~mm}$ ) were prepared by Spark Plasma Sintering (SPS), which is an advanced rapid processing technique for sintering advanced ceramic systems [27]. LABOX 350 (Sinter Land Inc., Japan) furnace was used for SPS. A pressure of 10-70 MPa was applied concurrently with the heating (rate 25-50 ${ }^{\circ} \mathrm{C} \mathrm{min}-1$ ) and released at the end of the sintering period, which was 8-60 min. Sintering temperature for all nanocomposites were in the range $1250-1450{ }^{\circ} \mathrm{C}$. For comparison, the prepared nanocomposite powders were also hot pressed at $10 \mathrm{MPa}$ in a graphite die $(20 \mathrm{~mm}$ in diameter) for 45-60 min. For SPS, a pulsed DC current with $5 \mu \mathrm{s}$ ON and $5 \mu \mathrm{s}$ OFF was used without any pause. Uniaxial hot press furnace, supplied by OXY-GON (USA) was used and to achieve optimal samples for comparison, the hot pressing temperature was in the range of $1250-1550{ }^{\circ} \mathrm{C}$. Alumina samples were also fabricated using the same SPS and hot pressing procedures but without any addition of graphene.

All of the sintered samples were ground using $\mathrm{SiC}$ paper down to 4000 grit. The density of the ground samples was measured using the Archimedes' water buoyancy method and also verified by a manual Heliulm multipycnometre (Quantachrome UK). All samples were then thoroughly dried in an oven for $24 \mathrm{~h}$ and then diamond polished using $1 \mu \mathrm{m}$ paste. Sintered nanocomposite samples were gently fractured and their micro structures were examined in an FE-SEM. Crosssectional surfaces were gold coated and observed in an ultrahigh resolution analytical FE-SEM (Hitachi, SU-70) using $20 \mathrm{keV}$. The Raman spectra were obtained on a Kaiser HoloLab 5000 system with an Nd:YAG laser excitation source of $532 \mathrm{~nm}(2.33 \mathrm{eV})$. The Raman laser was focussed on different areas of fracture surfaces, avoiding the near surface regions. Spectra were detected with an imaging photomultiplier $(1024 \times 1024)$ with $5 \mathrm{~cm}^{-1}$ resolution. Typical collection time was $70 \mathrm{~min}$ for each sample and at least 5 locations/ sample were examined for accurate quantification of the ratios of the intensities for different bands (i.e. $D, G$ and $G^{\prime}$ ). Thermogravimetric analysis (TGA) was conducted for all nanocomposites to evaluate graphene oxidation temperature using TA Instruments SDT Q600. Q500 (TA instruments) was used with a heating rate of $5{ }^{\circ} \mathrm{C} / \mathrm{min}$ to $1000{ }^{\circ} \mathrm{C}$ in air. All specimens were examined on platinum pans in the range 30 $1000{ }^{\circ} \mathrm{C}$. A heating rate of $5{ }^{\circ} \mathrm{C} / \mathrm{min}$ in flowing air (at $180 \mathrm{ml} /$ min) was used. Sample masses ranged from 40 to $50 \mathrm{mg}$ and at least 3 samples were oxidised for each composition of selected nanocomposites. For evaluating electrical conductivity, a bar (dimensions: $18 \times 3 \times 4 \mathrm{~mm}^{3}$ ) was cut from each sintered pellet using precision and deformation-free cutting machine (Accutom-50). At least 5 bars were produced for each composition and around $500 \mu \mathrm{m}$ of material was removed from all surfaces of sample by fine grinding. Four-point method [6] was employed by using a resistivity/ Hall measurement system (Quantum Design, PPMS, Model 6000) for measuring electrical conductivities of nanocomposites. For pure alumina samples, high resistance metre (HP 4329A) was used to measure the conductivity. The connecting wires in the 
experimental setup were permanently bonded by using silver paste in order to avoid any contact resistance for this comparative analysis.

\section{Results and discussion}

For structural and chemical preservation of graphene during sintering, the quality of vacuum or surrounding atmosphere is critical. A good vacuum $(5-10 \mathrm{~Pa})$ was used in this study to reduce any possible oxidation of graphene during sintering. Several alumina and nanocomposites were sintered to establish sintering conditions for preparing nanocomposite samples suitable for this study. Table 1 details the experimental conditions used for sintering alumina and alumina-3 vol\% graphene nanocomposites using Spark Plasma Sintering (SPS) and Hot Pressing (HP) techniques. The aim of this study was to compare samples processed SPS and HP techniques. SPS uses pulsed DC current whereas HP uses other non-pulsed heat conduction mechanisms for sintering ceramic and nanocomposite powders. As expected, a fully sintered nanocomposite sample (i.e. 2SN) was achieved using lower temperature and shorter duration for SPS, whereas higher temperature and longer durations were required for fully densifying sample $5 \mathrm{HN}$ using HP. However, to unequivocally correlate the nature of the sintering process to the quality of the graphene after densification, sample 6SN was SPSed using experimental variables (sintering duration, temperature, holding time, pressure and heating rate) identical to those used for hot-pressing sample 5HN. For comparing structural and crystalline stability of graphene in alumina matrix, fully dense nanocomposite samples were selected (i.e. highlighted in grey, Table 1).
Fig. 1 shows the FE-SEM images of fractured surfaces of the representative sintered nanocomposite samples. Individual layers of graphene are pointed and overall it can be observed that the graphene are well dispersed in the alumina matrix (Fig. 1). From the analysis of all fractured surfaces, where individual grains can be seen, intergranular fracture mode along with pulled out graphene from the alumina grains can be observed. Such refinement of microstructure due to the addition of carbon nanofillers has been previously reported $[8,28]$. A finer microstructure was observed for SPSed samples (Fig. 1a) as compared to hot-pressed sample (Fig. 1b). It can also be noted that all graphene layers were found crushed in between alumina grains which is also responsible for prevention of grain boundary movement. It should be noted here that from the FE-SEM analysis, it was not possible to visualise any structural differences between the postsintering conditions of graphene in 5SN and 5HN samples (Fig. 1).

Raman spectra of fully densified nanocomposites sintered using different processes are shown in Fig. 2. The alumina matrix was intentionally selected here because it produces no Raman signals for the studied frequency range. It is difficult to accurately quantify structural damage or crystallinity in graphene after sintering them with ceramic powder. However, Raman spectroscopy is a well-known and widely used characterisation technique for analysing carbon materials [29-35]. It is a versatile non-destructive technique for identifying multiple structural phases in graphene. For graphene, the D-band near $1370 \mathrm{~cm}^{-1}$ and the $\mathrm{D}^{\prime}$ shoulder band near $1630 \mathrm{~cm}^{-1}$ are, respectively, the disorder-induced features that are representing the intervalley $\mathrm{K} \rightarrow \mathrm{K}^{\prime}$ and intervalley $\mathrm{K}$ (or $\mathrm{K}^{\prime}$ ) double resonance scattering processes $[29,30]$. The most

Table 1

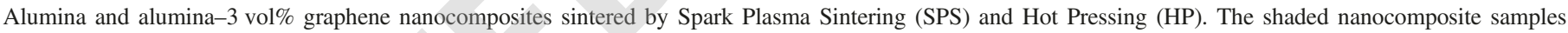
(fully densified) were considered in this study.

\begin{tabular}{|c|c|c|c|c|c|c|c|}
\hline Material & Sample ID & Process & $\begin{array}{l}\text { Max sintering } \\
\text { temperature }\left({ }^{\circ} \mathrm{C}\right)\end{array}$ & $\begin{array}{l}\text { Holding time at maximum } \\
\text { temperature (mins) }\end{array}$ & $\begin{array}{l}\text { Maximum } \\
\text { pressure }(\mathrm{MPa})\end{array}$ & $\begin{array}{l}\text { Heating rate } \\
\left({ }^{\circ} \mathrm{C} / \mathrm{min}\right)\end{array}$ & $\%$ Density \\
\hline Alumina & $1 \mathrm{HA}$ & HP & 1250 & 60 & 15 & 25 & 72.1 \\
\hline Alumina & $3 \mathrm{HA}$ & $\mathrm{HP}$ & 1250 & 60 & 15 & 25 & 75.1 \\
\hline Alumina & $2 \mathrm{H} 2$ & $\mathrm{HP}$ & 1250 & 45 & 25 & 25 & 76.1 \\
\hline Alumina & 3SA & SPS & 1250 & 8 & 50 & 50 & 88.4 \\
\hline Alumina & $4 \mathrm{HA}$ & HP & 1350 & 60 & 10 & 25 & 92.3 \\
\hline Alumina & $4 \mathrm{SA}$ & SPS & 1350 & 8 & 50 & 50 & 93.3 \\
\hline Alumina & $1 \mathrm{SA}$ & SPS & 1250 & 20 & 50 & 50 & 97.1 \\
\hline Alumina & $5 \mathrm{SA}$ & SPS & 1450 & 10 & 50 & 50 & 97.1 \\
\hline Alumina & $2 \mathrm{SA}$ & SPS & 1250 & 20 & 70 & 50 & 97.4 \\
\hline Alumina & $5 \mathrm{HA}$ & HP & 1450 & 60 & 10 & 25 & 98.1 \\
\hline Nanocomposite & $1 \mathrm{HN}$ & HP & 1250 & 60 & 15 & 25 & 75.4 \\
\hline Nanocomposite & $3 \mathrm{HN}$ & $\mathrm{HP}$ & 1250 & 60 & 15 & 25 & 80.1 \\
\hline Nanocomposite & $2 \mathrm{HN}$ & HP & 1250 & 45 & 25 & 25 & 80.2 \\
\hline Nanocomposite & $3 \mathrm{SN}$ & SPS & 1250 & 8 & 50 & 50 & 92.2 \\
\hline Nanocomposite & $4 \mathrm{HN}$ & HP & 1350 & 60 & 10 & 25 & 94.5 \\
\hline Nanocomposite & $4 \mathrm{SN}$ & SPS & 1350 & 8 & 50 & 50 & 96.4 \\
\hline Nanocomposite & $1 \mathrm{SN}$ & SPS & 1250 & 20 & 50 & 50 & 98.4 \\
\hline Nanocomposite & $2 \mathrm{SN}$ & SPS & 1250 & 20 & 70 & 50 & $>99.9$ \\
\hline Nanocomposite & $5 \mathrm{SN}$ & SPS & 1450 & 10 & 50 & 50 & $>99.9$ \\
\hline Nanocomposite & $5 \mathrm{HN}$ & HP & 1450 & 60 & 10 & 25 & $>99.9$ \\
\hline Nanocomposite & $6 \mathrm{SN}$ & SPS & 1450 & 60 & 10 & 25 & $>99.9$ \\
\hline Nanocomposite & $6 \mathrm{HN}$ & HP & 1550 & 60 & 10 & 25 & $>99.9$ \\
\hline
\end{tabular}



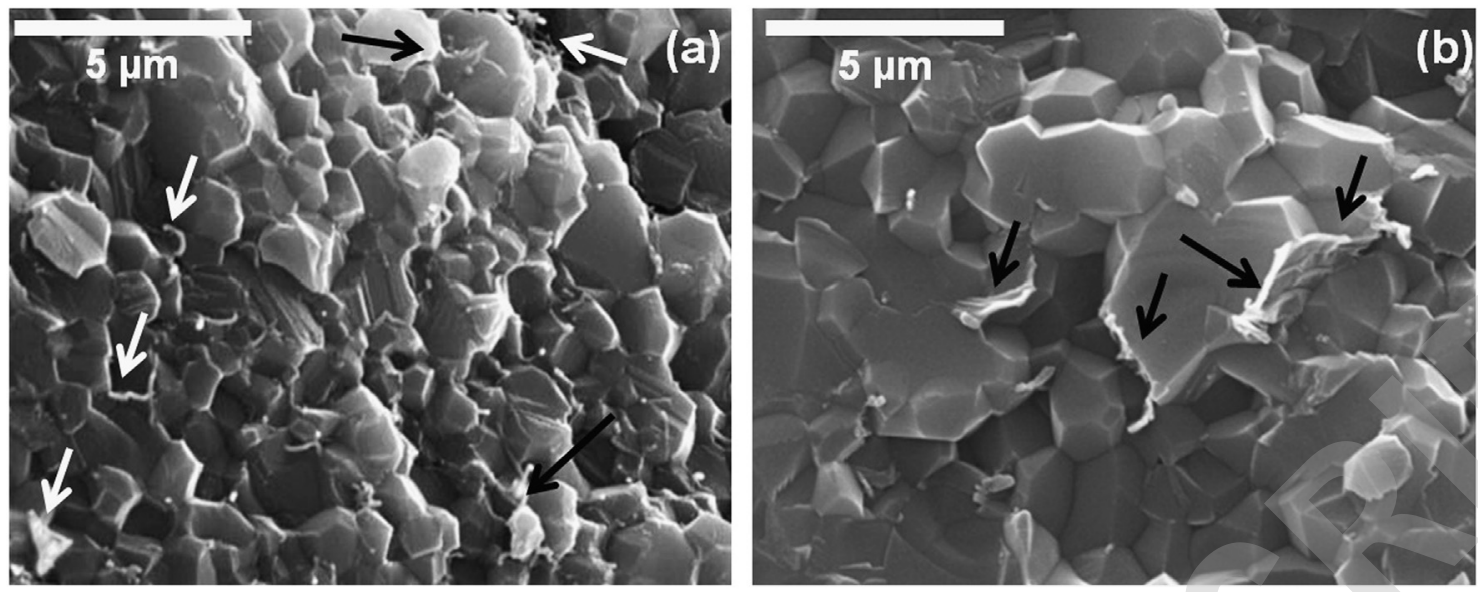

Fig. 1. Representative FE-SEM images showing graphene crushed between alumina grains: (a) sample 5SN sintered by SPS; (b) sample 5HN sintered by hot pressing.

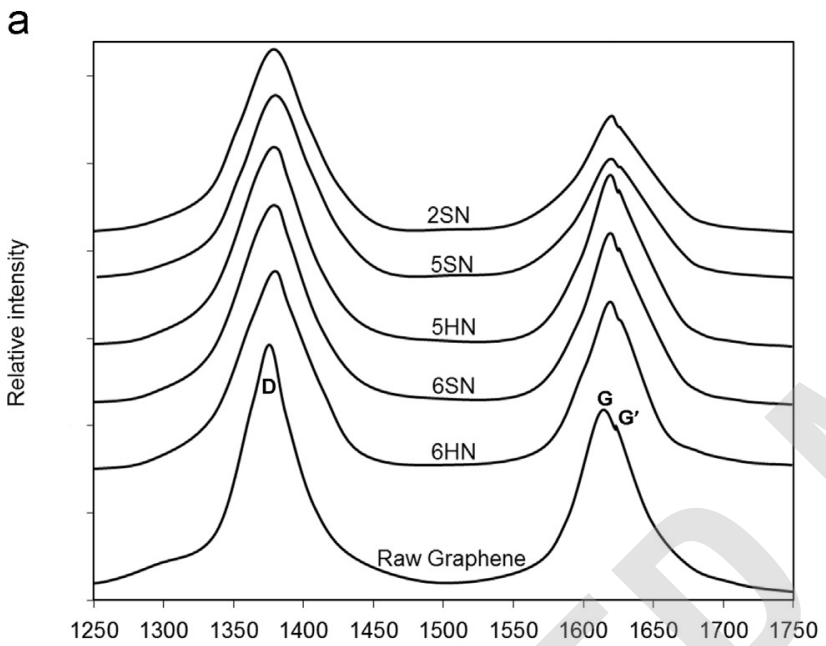

b

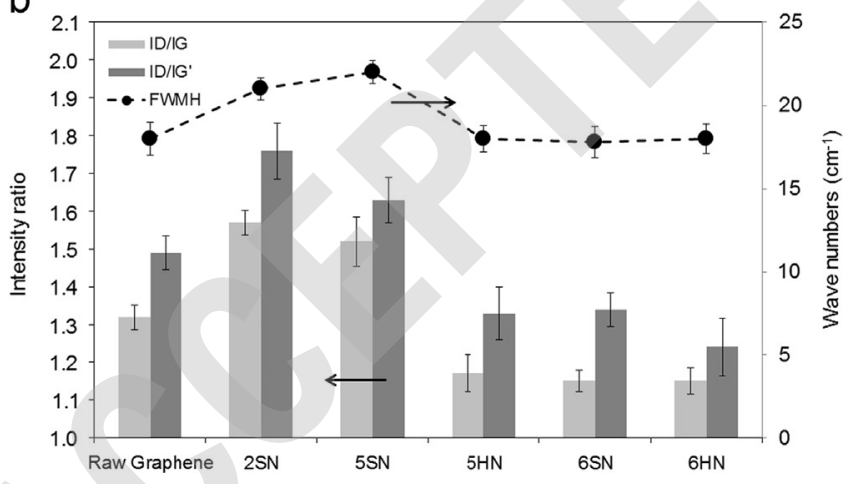

Fig. 2. Raman spectroscopy of raw graphene and fully densified nanocomposites: (a) spectra at low Raman frequencies; (b) analysis of intensity ratios and FWHM line widths for the $\mathrm{G}$ band.

prominent features in the Raman spectra of graphene is $\mathrm{G}$ band appearing at around $1620 \mathrm{~cm}^{-1}$, which is associated with the doubly degenerate phonon mode at the Brillouin zone centre or tangential vibration of carbon atoms [29]. The sharpening of G band peak will shorten FWHM (Full Width at Half Maximum) line which confirms the establishment of larger crystalline areas
[29,31]. Similarly, the D band is the signature of defects and increase in $I_{\mathrm{D}} / I_{\mathrm{G}}$ and $I_{\mathrm{D}} / I_{\mathrm{G}^{\prime}}$ corresponds to an increase in the amount of 'unorganised' carbon and/or decrease in the mean crystal size as reported elsewhere [31-35]. During graphitisation, the $I_{\mathrm{D}}$ becomes smaller than $I_{\mathrm{G}}$, which indicates a more perfect graphene structure $[31,33,35]$. Therefore, in this study, the authors used the $I_{\mathrm{D}} / I_{\mathrm{G}}$ and $I_{\mathrm{D}} / I_{\mathrm{G}^{\prime}}$ ratios and FWHM line widths from Raman spectroscopy supported by electrical conductivity and oxidation temperature analyses to study the degradation of graphene after sintering.

As evident in Fig. 2a, the D and G peaks of the graphene in the nanocomposites are slightly shifted compared to the unprocessed graphene because of residual stresses which is consistent with the previous studies for other types of carbon nanofillers $[32,36]$. From the closer inspection of $D$ and $G$ peaks for all nanocomposites, it was found that they are precisely at the same position. This means that all graphene observed for this study possess the same amount of residual stresses after sintering.

Fig. 2b shows analysis of ratios $\left(I_{\mathrm{D}} / I_{\mathrm{G}}\right.$ and $\left.I_{\mathrm{D}} / I_{\mathrm{G}^{\prime}}\right)$ and FWHM line widths for SPSed and HPed samples. In comparison to samples sintered using longer sintering durations, higher $I_{\mathrm{D}} / I_{\mathrm{G}}$ and $I_{\mathrm{D}} / I_{\mathrm{G}^{\prime}}$ ratios are observed for SPSed samples sintered using shorter sintering durations and lower temperature. Similarly, FWHM line widths were found broadened for SPSed samples sintered using shorter sintering durations and lower temperature as compared to samples densified using longer sintering durations $(5 \mathrm{HN}, 6 \mathrm{SN}$ and $6 \mathrm{HN})$, revealing amorphitisation or larger structural damage in graphene for SPSed samples (2SN and 5SN). From Raman spectroscopic analysis (Fig. 2b), a more perfect graphene structure was observed for HPed (5HN and 6HN) and SPSed (6SN) samples which is possibly due to graphitisation during longer sintering durations. All graphene dispersions were intensely tipsonicated prior to mixing with alumina powder, and there is a good possibility of creating structural damage during the process. However, graphene or any fullerene can go through thermally-induced structural transformations as previously reported $[33,37,38]$. Such structural transformations include 
higher degree of crystallinity or reduction in amorphous carbon $[31,39,40]$. Campos-Delgado et al. reported improved crystallinity for graphene ribbons when annealed to $1000{ }^{\circ} \mathrm{C}$ and $1500{ }^{\circ} \mathrm{C}$ for $30 \mathrm{~min}$ under argon atmosphere [31]. In comparison to Campos-Delgado et al.'s work [31], the experimental conditions used in this study are not identical (i.e. higher pressure and presence of ceramic powder/grains around graphene). However, evidence of improved crystallinity presented in Fig. 2 for samples 5HN, 6SN and $6 \mathrm{HN}$ reveals possible graphitisation and less damage to graphene as compared to SPSed samples (2SN and 5SN) fully sintered using shorter sintering durations. It should be noted that samples 2SN and 5SN are fully densified (Table 1) but the quality of graphene is poor possibly because of lack of graphitisation phenomenon.

Qualitative information on purity, crystallinity and structural health of graphene was obtained from the Thermogravimetric analysis (TGA) of the sintered nanocomposites. Higher the content of oxidisable residue and amorphous carbon, lower the onset of oxidation temperature or thermal stability and vice versa $[41,42]$. Fig. 3 shows the analysis of oxidation temperatures (onset points) for selected nanocomposites prepared by SPS and HP processes. It is clear from Fig. 3 that samples 2SN and $5 \mathrm{SN}$ have lower oxidation temperatures as compared to samples densified using longer sintering durations $(5 \mathrm{HN}, 6 \mathrm{SN}$ and $6 \mathrm{HN}$ ). For example, the difference between the oxidation temperatures for samples 5HN (HPed) and 5SN (SPSed) is around $25{ }^{\circ} \mathrm{C}$. This is due to the presence of higher number of crystalline regions in graphene graphitised during the lengthy sintering process of HP. However, insignificant difference in the oxidation temperature of $5 \mathrm{HN}$ and $6 \mathrm{SN}$ was observed.

Since all samples were sintered in reducing environment, surface carbonisation was visually confirmed for pure alumina samples. Alumina samples (5HA and 5SA) were found white in colour in the middle and grey on the edges. To diminish the effect of such carbonisation on the surfaces of nanocomposite samples, around $500 \mu \mathrm{m}$ of material was carefully removed prior to electrical conductivity measurements from all surfaces of the samples. The DC electrical conductivities of alumina-3 vol\% graphene nanocomposites are shown in Fig. 4. Disorder due to structural imperfection in graphene is responsible for lowering

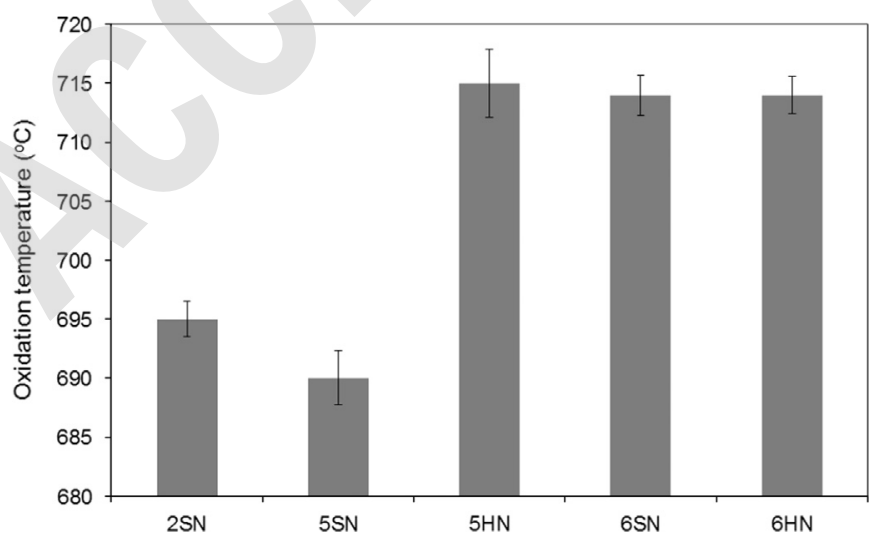

Fig. 3. Thermogravimetric analysis (TGA) of the sintered nanocomposites. electron mobility or reducing its electrical conductivity [43]. Therefore, for samples densified using longer sintering durations $(5 \mathrm{HN}, 6 \mathrm{SN}$ and $6 \mathrm{HN})$, the increase in electrical conductivity is due to the presence of more crystalline graphene with fewer defects. In contrast, the decreased electrical conductivities for 2SN and 5SN samples are attributed to the presence of damaged graphene, due to the utilisation of SPS technique or lack of graphitisation time during the sintering process (i.e. 10-20 min as compared to $60 \mathrm{~min}$ for samples $5 \mathrm{HN}, 6 \mathrm{SN}$ and $6 \mathrm{HN}$ ). It should also be noted that there was no significant difference for the electrical conductivities of samples $5 \mathrm{HN}$ and $6 \mathrm{SN}$ prepared by HP and SPS respectively. These observations are also consistent with the Raman spectroscopy and TGA analysis.

For SPS, there is very less known about the effect of DC pulsed current on the sintering of ceramics and their composites. For samples $5 \mathrm{HN}$ and $6 \mathrm{SN}$, identical experimental conditions were employed. The only difference was the type of the sintering process, i.e. HP for $5 \mathrm{HN}$ and SPS for $6 \mathrm{SN}$. From the comparison of samples $5 \mathrm{HN}$ and $6 \mathrm{SN}$, it was found that the structural health of graphene is almost the identical for both samples (Figs. 2-4). No significant differences can be observed from the thorough Raman spectroscopy, Thermogravimetric analyses and electrical conductivity analyses conducted in this study (Figs. 2-4). Therefore, it can be concluded that, in comparison to the sample sintered by HP (5HN), there is no additional effect of DC pulsed current on the structural stability of graphene for SPSed sample (6SN).

It should be noted that the purpose of this research was to compare structural health of graphene after sintering using SPS and HP. If it was only about producing fully densified nanocomposite samples, the sintering conditions used for 2SN and 5SN samples (by SPS) are ideal. Higher sintering rates and pressures were used for SPSing 2SN and 5SN which resulted in lower sintering durations (i.e. 20 and $10 \mathrm{~min}$ respectively). For these samples, there was no need to increase the sintering dwell time and temperature as we did for sample 6SN. Therefore, it can be summarised that SPS can not only be used to produce samples rapidly but can be further be used for in-situ crystallisation of graphene during the sintering of ceramic nanocomposites as evident from Raman spectroscopy,

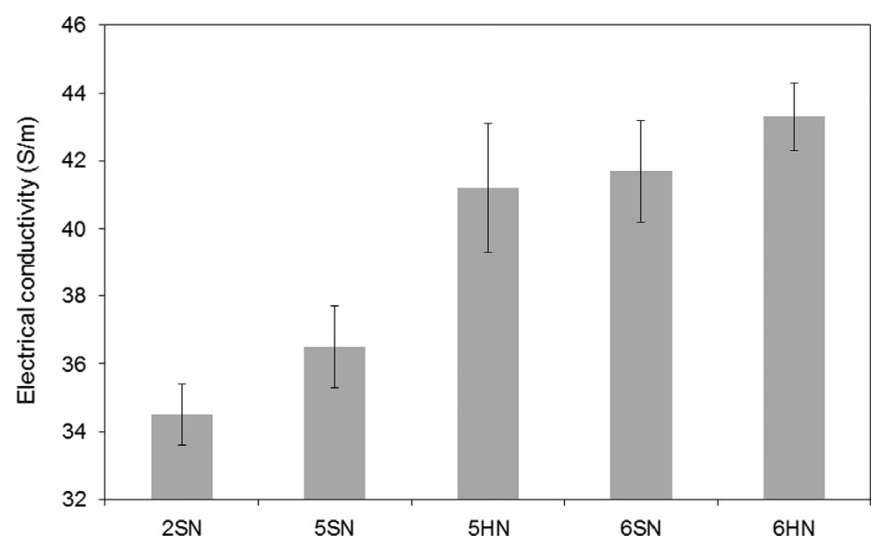

Fig. 4. Electrical conductivities of sintered nanocomposites measured by fourprobe method. 
Thermogravimetric analyses and electrical conductivity analyses. This confirms the versatility and effectiveness of SPS processing over other conventional sintering techniques for producing advanced ceramics and their nanocomposites.

\section{Conclusion}

It is widely believed that SPS is always a better technique to prepare ceramic nanocomposites filled with carbon nanofillers. The evidence of such belief can be witnessed from recent publications processing ceramic-graphene nanocomposites. However, to the best of our knowledge, no research group has carried out a comprehensive comparison of the postsintering structural health of graphene in nanocomposites sintered with SPS and HP processing methods. In this study, graphene in HPed and SPSed samples sintered using longer sintering durations were found to possess higher crystallinity, thermal stability and electrical conductivity as compared to SPSed samples produced using shorter sintering durations. This was attributed to the thermally induced graphitisation caused by longer sintering durations for samples $(5 \mathrm{HN}, 6 \mathrm{SN}$ and $6 \mathrm{HN}$ ), which was lacking in SPSed samples (2SN and $5 \mathrm{SN})$. Existence of higher purity and crystallinity was confirmed from Raman spectroscopy, Thermogravimetric analyses and electrical conductivity analyses. Therefore, it is concluded from this study that SPS is an efficient tool for controlled reconstruction of graphene and thus for modification for its properties during sintering for alumina-graphene nanocomposites. SPS can not only be used to making fully densified samples at lower temperatures and shorter durations, but can also be used for in-situ graphitisation of graphene during the sintering process. It was also concluded that there is no additional effect of DC pulsed current on the structural stability of graphene for nanocomposites samples prepared by SPS.

\section{Acknowledgement}

Dr. Inam would like to thank the Department of Mechanical and Construction Engineering, Northumbria University, UK for the travel grant, without which the experimental characterisations were not possible.

\section{References}

[1] C. Lee, X. Wei, J.W. Kysar, J. Hone, Measurement of the elastic properties and intrinsic strength of monolayer graphene, Science 321 (2008) 385 .

[2] M. Zhou, B. Hui, T. Lin, X. Lü, F. Huang, J. Lin, Directional architecture of graphene/ceramic composites with improved thermal conduction for thermal applications, J. Mater. Chem. A 2 (2014) 2187-2193.

[3] P. Miranzo, C. Ramírez, B.R. Manso, et al., In situ processing of electrically conducting graphene/SiC nanocomposites, J. Eur. Ceram. Soc. 33 (10) (2013) 1665-1674.

[4] L.S. Walker, V.R. Marotto, M.A. Rafiee, N. Koratkar, E.L. Corral, Toughening in graphene ceramic composites, ACS Nano 5 (4) (2011) 3182-3190.

[5] Andy Nieto, Debrupa Lahiri, Arvind Agarwal, Graphene nano platelets reinforced tantalum carbide consolidated by spark plasma sintering, Mater. Sci. Eng. A 582 (2013) 338-346.
[6] Fawad Inam, Badekai Bhat, V.o. Thuc, Daoush Walid, Structural health monitoring capabilities in ceramic-carbon nanocomposites, Ceram. Int.0272-884240 (2) (2014) 3793-3798.

[7] G.B. Yadhukulakrishnan, S. Karumuri, A. Rahman, R.P. Singh, A.K. Kalkan, S.P. Harimkar, Spark plasma sintering of graphene reinforced zirconium diboride ultra-high temperature ceramic composites, Ceram. Int. 39 (6) (2013) 6637-6646.

[8] J. Liu, H. Yan, M.J. Reece, K. Jiang, Toughening of zirconia/alumina composites by the addition of graphene platelets, J. Eur. Ceram. Soc. 32 (16) (2012) 4185-4193.

[9] H. Liem, H.S. Choy, Superior thermal conductivity of polymer nanocomposites by using graphene and boron nitride as fillers, Solid State Commun. 163 (2013) 41-45.

[10] Vivek Dhand, Kyong Yop Rhee, Hyun Ju Kim, Dong Ho Jung, A comprehensive review of graphene nanocomposites: research status and trends, J. Nanomater. 2013 (2013) 14 (Article ID 763953).

[11] H. Porwal, S. Grasso, M.J. Reece, Review of graphene-ceramic matrix composites, Adv. Appl. Ceram. 112 (8) (2013) 443-454.

[12] G.L. Hwang, K.C. Hwang, Carbon nanotube reinforced Ceramics, J. Mater. Chem. 11 (6) (2001) 1722-1725.

[13] F. Inam, H. Yan, M.J. Reece, T. Peijs, Structural and chemical stability of multiwall carbon nanotubes in sintered ceramic nanocomposite, Adv. Appl. Ceram. 109 (4) (2010) 240-245.

[14] A. Peigney, E. Flahaut, C. Laurent, F. Chastel, A. Rousset, Aligned carbon nanotubes in ceramic-matrix nanocomposites prepared by hightemperature extrusion, Chem. Phys. Lett. 352 (1-2) (2002) 20-25.

[15] A.R. Boccaccini, D.R. Acevedo, G. Brusatin, P. Colombo, Borosilicate glass matrix composites containing multi-wall carbon nanotubes, J. Eur. Ceram. Soc. 25 (9) (2005) 1515-1523.

[16] E. Flahaut, A. Peigney, C. Laurent, C. Marliere, F. Chastel, A. Rousset, Carbon nanotube-metal-oxide nanocomposites: microstructure, electrical conductivity and mechanical properties, Acta Mater. 48 (14) (2000) 3803-3812.

[17] J. Sun, L. Gao, Development of a dispersion process for carbon nanotubes in ceramic matrix by heterocoagulation, Carbon 41 (5) (2003) $1063-1068$.

[18] S. Rul, F. Lefevre-schlick, E. Capria, C. Laurent, A. Peigney, Percolation of single-walled carbon nanotubes in ceramic matrix nanocomposites, Acta Mater. 52 (4) (2004) 1061-1067.

[19] P. Rutkowski, L. Stobierski, G. Górny, Thermal stability and conductivity of hot-pressed $\mathrm{Si}_{3} \mathrm{~N}_{4}$-graphene composites, J. Therm. Anal. Calorim. 116 (2014) 321-328.

[20] S. Baradaran, E. Moghaddam, W.J. Basirun, M. Mehrali, M. Sookhakian, M. Hamdi, M.R. Nakhaei Moghaddam, Y. Alias, Mechanical properties and biomedical applications of a nanotube hydroxyapatite-reduced graphene oxide composite, Carbon 69 (2014) 32-45.

[21] Mehdi Mehrali, Ehsan Moghaddam, Seyed Farid Seyed Shirazi, Saeid Baradaran, Mohammad Mehrali, Sara Tahan Latibari, Hendrik Simon Cornelis Metselaar, Nahrizul Adib Kadri, Keivan Zandi, Noor Azuan Abu Osman, Synthesis, mechanical properties and in vitro biocompatibility with osteoblasts of calcium silicate reduced graphene oxide composites, ACS Appl. Mater. Interfaces 6 (2014) 3947-3962.

[22] Lenka Kvetková, Annamária Duszová, Monika Kašiarová, Františka Dorčáková, J.á.n. Dusza, Csaba Balázsi, Influence of processing on fracture toughness of $\mathrm{Si}_{3} \mathrm{~N}_{4}+$ graphene platelet composites, J. Eur. Ceram. Soc. 33 (12) (2013) 2299-2304.

[23] O. Tapasztó, P. Kun, F. Wéber, G. Gergely, K. Balázsi, J. Pfeifer, P. Arató, A. Kidari, S. Hampshire, C. Balázsi, Silicon nitride based nanocomposites produced by two different sintering methods, Ceram. Int. 37 (2011) 3457-3461.

[24] A. Centeno, V.G. Rocha, B. Alonso, A. Fernández, C.F. Gutierrez-Gonzalez, R. Torrecillas, A. Zurutuza, Graphene for tough and electroconductive alumina ceramics, J. Eur. Ceram. Soc. 33 (15-16) (2013) 3201-3210.

[25] J. Campos-Delgado, et al., Bulk production of a new form of Sp2 carbon: crystalline graphene nanoribbons, Nano Lett. 8 (2008) 2773.

[26] F. Inam, H. Yan, M. Reece, T. Peijs, Dimethylformamide: an effective dispersant for making ceramic-carbon nanotube composites, Nanotechnology 19 (19) (2008) 195710. 
[27] H.F. Jackson, D.D. Jayaseelan, W.E. Lee, M.J. Reece, F. Inam, D. Manara, et al., Laser melting of spark plasma-sintered zirconium carbide: thermophysical properties of a generation IV very hightemperature reactor material, Int. J. Appl. Ceram. Technol. 7 (3) (2010) 316-326 , http://onlinelibrary.wiley.com/doi/10.1111/j.1744-7402.2009. 02434.x/abstract.

[28] F. Inam, T. Peijs, M.J. Reece, The production of advanced fine-grained alumina by carbon nanotube addition, J. Eur. Ceram. Soc. 31 (15) (2011) 2853-2859.

[29] L.M. Malard, M.A. Pimenta, G. Dresselhaus, M.S. Dresselhaus, Raman spectroscopy in graphene, Phys. Rep. 473 (2009) 51-87.

[30] R. Saito, A. Grüneis, G.e.G. Samsonidze, V.W. Brar, G. Dresselhaus, M. S. Dresselhaus, A. Jorio, L.G. Cançado, C. Fantini, M.A. Pimenta, A G. Souza Filho, Double resonance Raman spectroscopy of single-wall carbon nanotubes, N. J. Phys. 5 (2003) 1571.

[31] J. Campos-Delgado, Y.A. Kim, T. Hayashi, A. Morelos-Gomez, M. Hofmann, H. Muramatsu, M. Endo, H. Terrones, R.D. Shull, M. S. Dresselhaus, M. Terrones, Thermal stability studies of CVD-grown graphene nanoribbons: defect annealing and loop formation, Chem. Phys. Lett. 469 (2009) 177-182.

[32] F. Inam, H. Yan, M.J. Reece, T. Peijs, Structural and chemical stability of multiwall carbon nanotubes in sintered ceramic nanocomposite, Adv. Appl. Ceram. 109 (4) (2010) 240-247.

[33] M. Endo, Y.A. Kim, T. Hayashi, Y. Fukai, K. Oshida, M. Terrones, T. Yanagisawa, S. Higaki, M.S. Dresselhaus, Structural characterization of cup-stacked-type nanofibers with an entirely hollow core, Appl. Phys. Lett. 80 (2002) 1267.
[34] F. Tuinstra, J.L. Koenig, Raman spectrum of graphite, J. Chem. Phys. 53 (1970) 1126-1130.

[35] P. Delhaes, M. Couzi, M. Trinquecoste, J. Dentzer, H. Hamidou, C. V. Guterl, A comparison between Raman spectroscopy and surface characterizations of multiwall carbon nanotubes, Carbon 44 (2006) 3005-3013.

[36] R. Poyato, A.L. Vasiliev, N.P. Padture, H. Tanaka, T. Nishimura, Aqueous colloidal processing of single-wall carbon nanotubes and their composites with ceramics, Nanotechnology 17 (2006) 1770-1777.

[37] H. Murayama, T. Maeda, A novel form of filamentous graphite, Nature 345 (1990) 791

[38] Y. Gogotsi, J.A. Libera, N. Kalashnikov, M. Yoshimura, Graphite polyhedral crystals, Science 290 (2000) 317-320.

[39] Y.S. Park, Y.C. Choi, K.S. Kim, et al., High yield purification of multiwalled carbon nanotubes by selective oxidation during thermal annealing, Carbon 39 (5) (2001) 655-661.

[40] I.W. Chiang, B.E. Brinson, R.E. Smalley, J.L. Margrave, R.H. Hauge, Purification and characterization of single-wall carbon nanotubes, J. Phys. Chem. B 105 (2001) 1157.

[41] K.E. Hurst, A. Van Der Geest, M. Lusk, E. Mansfield, J.H. Lehman, Quartz-crystal microbalance for in situ monitoring of laser cleaning of carbon nanotubes, Carbon 48 (9) (2010) 2521-2525.

[42] Dilip K. Singh, Parameswar K. Iyer, P.K. Giri, Diameter dependence of oxidative stability in multiwalled carbon nanotubes: role of defects and effect of vacuum annealing, J. Appl. Phys. 108 (2010) 084313.

[43] M. Sprinkle, M. Ruan, Y. Hu, J. Hankinson, M. Rubio-Roy, B. Zhang, X. Wu, C. Berger, W.A. de Heer, Scalable templated growth of graphene nanoribbons on SiC, Nat. Nanotechnol. 5 (2010) 727-731. 